\title{
Responses of Green Leaves and Green Pseudobulbs of CAM Orchid Cattleya laeliocattleya Aloha Case to Drought Stress
}

\author{
Jie He, Hazelman Norhafis, and Lin Qin \\ Natural Sciences and Science Education Academic Group, National Institute of Education, Nanyang Technological University, \\ 1 Nanyang Walk, Singapore 637616 \\ Correspondence should be addressed to Jie He; jie.he@nie.edu.sg
}

Received 27 January 2013; Accepted 24 June 2013

Academic Editor: Akira Nagatani

Copyright (C) 2013 Jie He et al. This is an open access article distributed under the Creative Commons Attribution License, which permits unrestricted use, distribution, and reproduction in any medium, provided the original work is properly cited.

This study examined the responses of green leaves (GL) and green pseudobulbs (GPSB) of CAM orchid Cattleya laeliocattleya Aloha Case to drought stress. After being subjected to drought stress, the decrease in water content (WC) was much greater in GPSB than in GL, indicating that GPSB facilitated a slow reduction in the WC of GL. This finding was further supported by the result of relative water content (RWC) of GL, which started to decrease only after 3 weeks of drought stress. Decreases of midday $F_{v} / F_{m}$ ratios of GL occurred in all plants. However, the degrees of decrease were much greater in drought-stressed GL than in well-watered GL. Reduced $F_{v} / F_{m}$ ratio $(<0.8)$ at early morning was observed in drought-stressed GL after 3 weeks of treatments. Decreases in total chlorophyll $(\mathrm{Chl})$ content, electron transport rate (ETR), photochemical quenching, $\mathrm{qP}$, and nonphotochemical quenching, $\mathrm{qN}$, were severer in GPSB than in GL after drought treatment. CAM acidity was significantly lower in both GL and GPSB after 2 weeks of drought treatment compared to well-watered plants. However, decrease of CAM acidity was smaller in GL than in GPSB. These results suggest that both GL and GPSB of CAM orchid Cattleya plantswere susceptible to drought stress.

\section{Introduction}

Epiphytic orchids found in tropical environments are directly or indirectly exposed to natural air currents and solar radiation and receive only intermittent rains. In addition to coping with rapid changes in natural air current and light intensity, there is also the need for epiphytic orchids to adapt to periodic drought [1]. Many epiphytic orchids develop morphological features to conserve and/or store water to cope with drought. A morphological feature includes the presence of swollen stems called pseudobulbs that serve as a reserve for water and carbohydrates [2].

Among the many abiotic factors involved in the survival of epiphytes, water availability is probably the most important environmental factor limiting growth and survival of epiphytes [3]. Thus, tolerance to water deficit is a decisive factor in their survival. The presence of the pseudobulb may facilitate a slow reduction in the leaf water content and decline in water potential during a period of drought $[1,4,5]$. The pseudobulb is characterized by the presence of very thick cuticle, absence of stomata, and the abundance of water-storing cells [6]. This makes the pseudobulb an integral organ in the survival and growth of orchids $[7,8]$. This is even more so for green pseudobulbs (GPSB) which can photosynthesise and hence contribute positively to carbon balance.

Although large amounts of water and carbohydrates are stored in the GPSB, many epiphytic orchids are sensitive to prolonged water deficit $[9,10]$. Under conditions of water deficit, photosynthetic capacities in terms of utilization of radiant energy and carbon fixation of GL and GPSB may be reduced under drought stress. However, photosynthetic responses of GL and GPSB of CAM orchid plants to drought stress are poorly understood. The main objective of this study was first to investigate the effects of drought stress on the water status of both GL and GPSB of CAM orchid Cattleya laeliocattleya Aloha Case. To investigate the water status of plants, WC was determined for both GPSB and GL after the plants were subjected to drought stress. The massive reduction of WC in plants can have a negative impact on cell expansion and cell growth, resulting in overall 
growth reduction [11]. Compared to WC, RWC is considered a better indicator of plant water status, which measures the absolute content of water in fresh plant tissues relative to the maximum WC in the tissues at full turgidity [11]. It has been reported that well-watered plants have RWC values between $85 \%$ and $95 \%$ whereas RWC can decrease up to $40 \%$ in severely drought-stressed plants [12]. Therefore, RWC was determined but only for GL as it is not feasible to do this measurement for GPSB. In this study, photosynthetic utilization of radiant energy was also addressed through the measurements of photosynthetic pigments and the various chlorophyll fluorescence parameters [13]. The decrease in photosynthetic light use efficiency caused by drought could affect the carbon fixation measured by CAM acidity, and ultimately, the growth and development of plants $[14,15]$. Hence, CAM acidity was also determined after the plants were subjected to drought stress.

\section{Materials and Methods}

2.1. Plant Material. Mature plants of CAM orchid Cattleya laeliocattleya Aloha Case were obtained from a commercial nursery. Each plant consisted of a single succulent green leaf (GL), a green pseudobulb (GPSB), and varying numbers of roots. The plants were repotted with around 2-3 plants per pot and allowed to acclimatize for four weeks in the plant physiology house at the National Institute of Education, Singapore, with a maximal photosynthetic photon flux density (PPFD) of 700 to $800 \mu \mathrm{mol} \mathrm{m} \mathrm{m}^{-2} \mathrm{~s}^{-1}$ and a daily temperature which ranged from $24^{\circ} \mathrm{C}$ to $33^{\circ} \mathrm{C}$. During the four weeks of acclimatization, all plants were watered twice daily at $0800 \mathrm{~h}$ and $1700 \mathrm{~h}$, respectively. At the end of the week, fertilizers and pesticides were sprayed to the leaves.

2.2. Drought Stress Treatment. The experiment was designed to study the course of changes in physiology occurring in both GL and GPSB during drought stress. After four weeks of acclimatization, one half of the plants were subjected to drought stress (no watering), while the other half of the plants were kept well watered (control) twice daily as described above. The period of drought stress was four weeks.

2.3. Measurement of WC. Fresh weight (FW) of plant tissues was recorded using a weighing balance (Sartorius, Fisher General Scientific Private Limited, Singapore) before being wrapped in aluminium foil and dried in an oven at $105^{\circ} \mathrm{C}$ for $48 \mathrm{~h}$. Samples were then weighed to determine dry weight (DW). WC was expressed as (FW - DW)/FW.

2.4. Measurement of RWC. A small portion of GL was cut and immediately weighed with an analytical balance to determine FW. The sample was floated on water in the dark for $24 \mathrm{~h}$ prior to measurement of its saturated weight (SW). The sample was then dried in the oven at $105^{\circ} \mathrm{C}$ for $48 \mathrm{~h}$ to obtain its DW. RWC was calculated as RWC $=(\mathrm{FW}-\mathrm{DW}) /(\mathrm{SW}-\mathrm{DW}) \times 100 \%$.

2.5. Measurement of Chl Fluorescence $F_{v} / F_{m}$ Ratio. Readings were taken every two hours from 0800 to $1800 \mathrm{~h}$ after 1,2 ,
3 , and 4 weeks of drought stress treatment, respectively. All measurements were made with Plant Efficiency Analyzer (PEA, Hansatech Instruments Ltd., England). The GL were predarkened with clips for $15 \mathrm{~min}$ prior to measurement and then placed under the light pipe and irradiated with the pulsed lower intensity-measuring beam to measure $F_{0}$, initial Chl fluorescence. $F_{m}$, maximum $\mathrm{Chl}$ fluorescence, was assessed by $0.8 \mathrm{~s}$ of saturated pulse $(>3000 \mu \mathrm{mol}$ photon $\left.\mathrm{m}^{-2} \mathrm{~s}^{-1}\right)$. The variable fluorescence yield, $F_{v}$, was determined by $F_{m}-F_{0}$. The efficiency of excitation energy captured by open photosystem II (PSII) reaction centers in dark adapted plant samples was estimated by the fluorescence $\left(F_{v} / F_{m}\right.$ ratio).

2.6. Measurement of Electron Transport Rate (ETR), Photochemical Quenching ( $q P)$, and Nonphotochemical Quenching $(q N)$. For these measurements, GL and GPSB were harvested at $0730 \mathrm{~h}$ and were predarkened under a black cloth for $15 \mathrm{~min}$ prior to measurements. ETR, qP, and $\mathrm{qN}$ were determined using the Imaging Pam Chl Fluorometer (Walz, Effeltrich, Germany) at $25^{\circ} \mathrm{C}$ under different PPFDs in the laboratory as described by He et al. [13].

2.7. Measurement of CAM Acidity (Titratable Acidity, TA). TA was determined at both $0800 \mathrm{~h}$ and $1800 \mathrm{~h} .1 \mathrm{~g}$ of GL and GPSB was transferred into heat tolerant tubes containing $1 \mathrm{ml}$ of distilled water (neutral $\mathrm{pH}$ ) and immersed into a boiling water bath for $15 \mathrm{~min}$. The tubes were allowed to cool and were subsequently titrated against $0.01 \mathrm{M}$ sodium hydroxide solution, $\mathrm{NaOH}(\mathrm{aq})$, using three drops of phenolphthalein as an indicator. The volume of $\mathrm{NaOH}(\mathrm{aq})$ needed to reach the end point was recorded. The samples were then dried at $80^{\circ} \mathrm{C}$ to obtain the weight of dry matter (DM). TA was calculated using the formula TA $=(0.01 \times$ volume $) / D M$. CAM acidity, which was the dawn/dusk fluctuation of TA, was calculated from the difference between TA at $0800 \mathrm{~h}$ and $1800 \mathrm{~h}$.

2.8. Measurements of Chl Content. $0.05 \mathrm{~g}$ of each GL and GPSB sample was weighed and cut into smaller pieces. Chl content was extracted from these samples using dimethylformamide and quantified spectrophotometrically at wavelengths of 647 and $664 \mathrm{~nm}$ [16].

2.9. Statistical Analysis. A $t$-test was used to test for the differences between well-watered and drought-stressed GL or GPSB (MINITAB, Inc., Release 15, 2007).

\section{Results}

3.1. WC and RWC of GL and GPSB after Drought Stress Treatment. During a 4-week period of drought stress treatment, decrease in WC was much greater in GPBS than in GL of drought-stressed plants. For instance, compared to wellwatered plants, significant decrease of WC was observed in GPSB of drought-stressed plants after two weeks of treatment $(P<0.05)$ while reduced WC was observed in GL only after 3 weeks $(P<0.05)$ of drought stress (Figure 1(a)). It was also shown that RWC of GL was still about $80 \%$ after 2 weeks of 


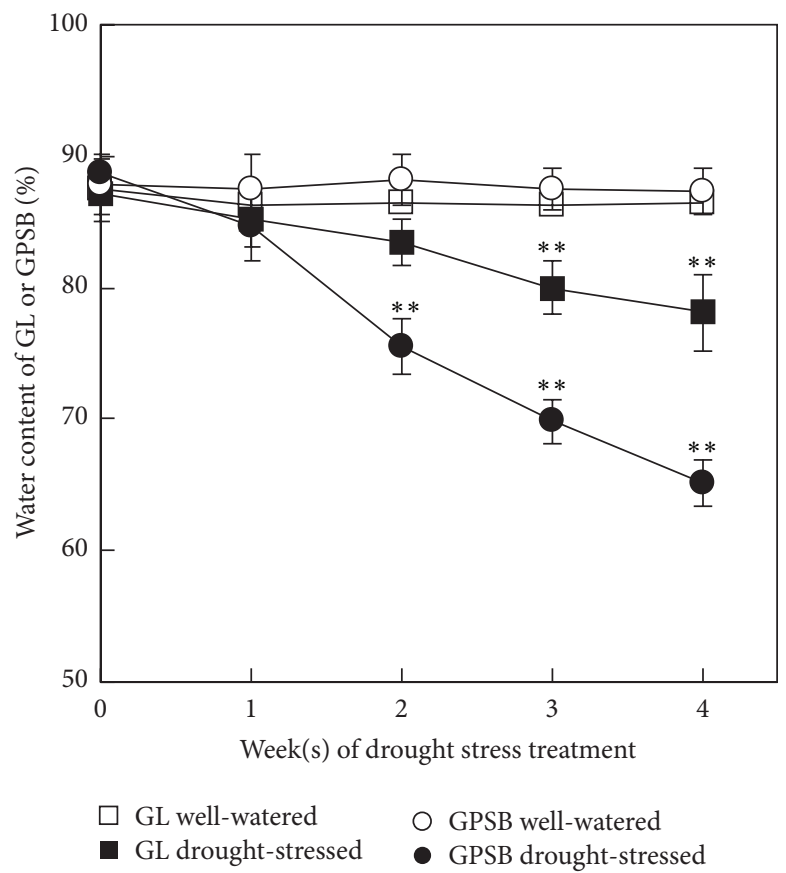

(a)

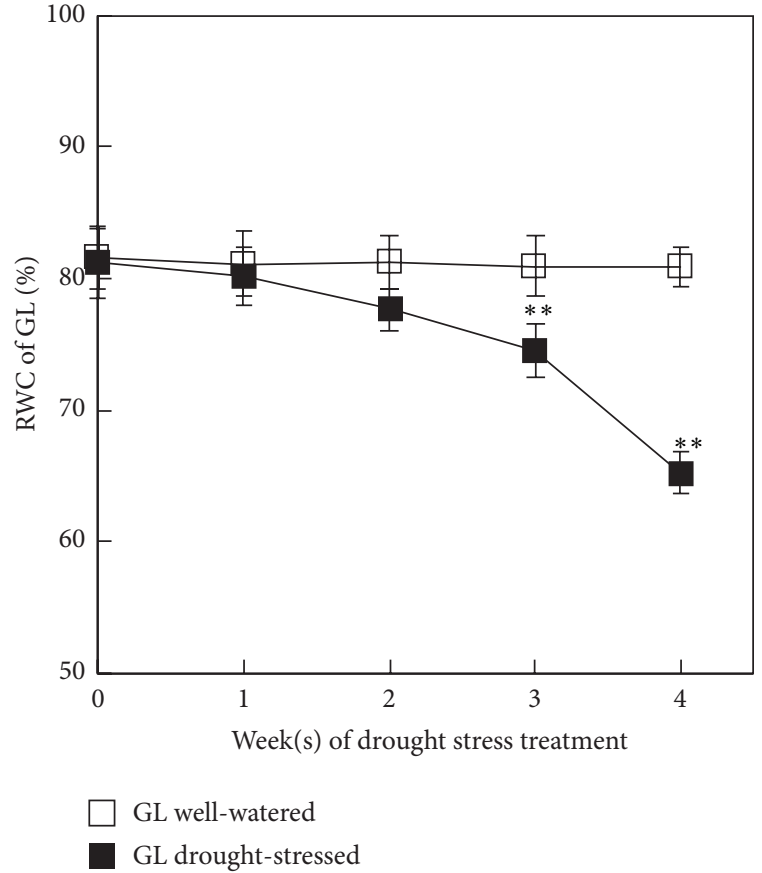

(b)

FIGURE 1: Changes in WC of GL and GPBS (a) and RWC (b) of GL during a drought stress period in well-watered and drought-stressed CAM orchid Cattleya laeliocattleya Aloha Case plants. Each point is the mean of 6 measurements from 6 different plants. Vertical bars represent standard errors. When the standard error bars cannot be seen, they are smaller than the symbols. ${ }^{* *}$ Above the means of drought-stressed GL and GPSB are statistically different from their well-watered control plants, respectively $(P<0.05)$.

drought stress, and it only started to decrease after 3 weeks of drought treatment (Figure 1(b)).

3.2. Diurnal Changes of Chl Fluorescence $F_{v} / F_{m}$ Ratio of $G L$ after Drought Stress Treatment. $F_{v} / F_{m}$ ratio assesses whether the stress experienced by a plant affects photosynthetic light utilization [13]. As it was not feasible to measure $F_{v} / F_{m}$ ratio from intact GPSB, diurnal changes of $F_{v} / F_{m}$ ratio were only monitored from the same position of GL after drought stress treatment for 1, 2, 3, and 4 weeks, respectively. Although midday depression of $F_{v} / F_{m}$ ratios was recorded in GL with lower values in drought-stressed GL than in well-watered GL after 1 and 2 weeks of treatment $(P<0.05)$, there were no significant differences in all $F_{v} / F_{m}$ ratios during early morning from the same GL (Figures 2(a) and 2(b)). However, significant difference in $F_{v} / F_{m}$ ratios between GL and GPSB was observed throughout the day $(P<0.05)$ after 3 and 4 weeks of treatment (Figures 2(c) and 2(d)). The differences in $F_{v} / F_{m}$ ratios between well-watered and drought-stressed GL were much greater after 4 weeks (Figure 2(d)) than after 3 weeks (Figure 2(c)) of treatment.

3.3. ETR, $q P$, and $q N$ of GL and GPSB after Drought Stress Treatment. Differences in photosynthetic light utilization between GL and GPSB after drought stress treatments were studied by measuring ETR, $\mathrm{qP}$, and $\mathrm{qN}$ under different PPFDs in the laboratory. The measurements were carried out after 2 and 3 weeks as samples of GPSB were severely damaged after 4 weeks of treatment. For well-watered plants, ETR of GL increased with increasing PPFD from 25 to $600 \mu \mathrm{mol} \mathrm{m}^{-2} \mathrm{~s}^{-1}$ and then decreased with further increasing PPFD when they were measured under PPFDs $>600 \mu \mathrm{mol} \mathrm{m}^{-2} \mathrm{~s}^{-1}$ (Figures $3(\mathrm{a})$ and $3(\mathrm{c}))$. For GPSB of well-watered plants, although their light response curves were similar to those of GL, their highest ETR values were recorded under PPFD of about $400 \mu \mathrm{mol} \mathrm{m}^{-2} \mathrm{~s}^{-1}$ (Figures 3(b) and 3(d)). There were no significant differences in ETR in GL between well-watered and drought-stressed plants $(P>0.05)$ after 2 weeks of drought stress (Figure 3(a)) while a significant lower ETR was measured under PPFDs $>250 \mu \mathrm{mol} \mathrm{m}^{-2} \mathrm{~s}^{-1}$ in droughtstressed GL than in well-watered GL after 3 weeks of treatment (Figure 3(c)). For GPSB, a significant lower ETR was measured in drought-stressed plants than in well-watered plants when they were measured under PPFDs greater than 200 and $400 \mu \mathrm{mol} \mathrm{m}^{-2} \mathrm{~s}^{-1}$, respectively (Figures 3(b) and 3(d)). For both GL and GPSB, qP decreased with increasing PPFD for all plants (Figure 4). For GL, there were no differences in $\mathrm{qP}$ between well-watered and drought-stressed plants $(P>0.05)$ after 2 weeks of treatment (Figure 4(a)). However, qP values were significantly lower $(P<0.05)$ in GL of drought-stressed than that of well-watered plants (Figure 4(c)). For GPSB, qP values of drought-stressed plants were significantly lower $(P<0.05)$ in drought-stressed plants than in well-watered plants after 2 and 3 weeks of treatment (Figures $4(\mathrm{~b})$ and $4(\mathrm{~d})$ ). These results show that GPSB have a lower light utilization compared to that of GL, 


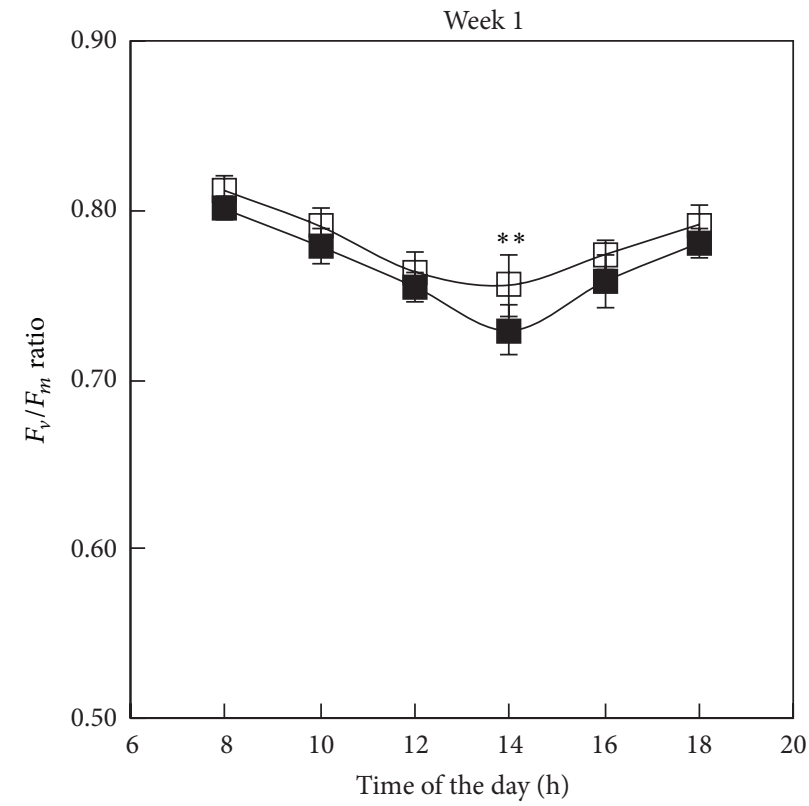

GL well-watered

GL drought-stressed

(a)

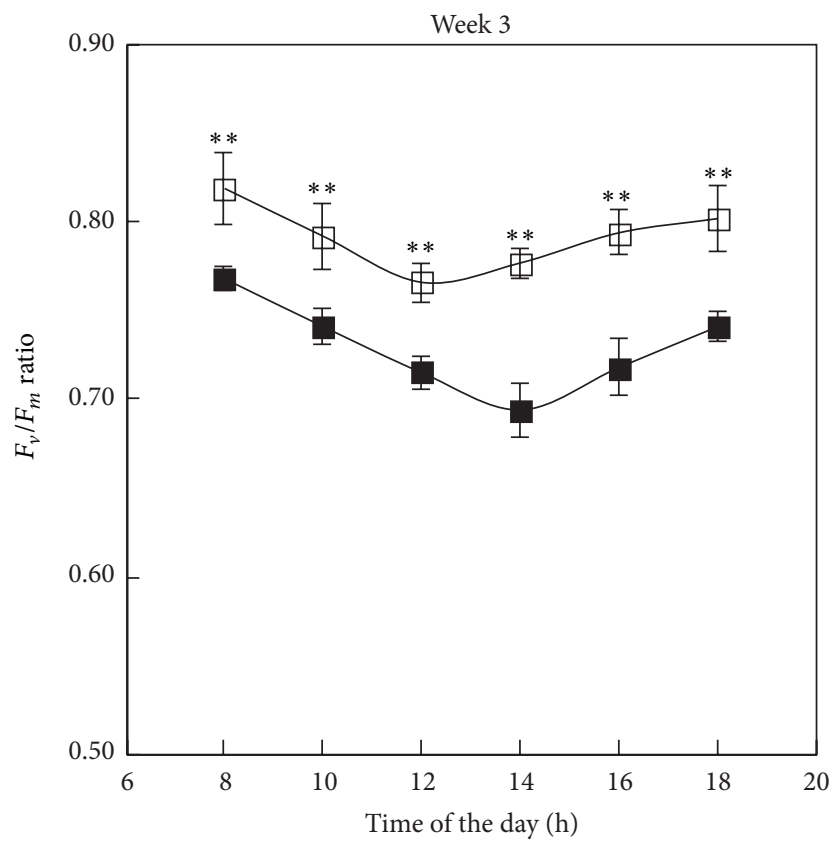

GL well-watered

GL drought-stressed

(c)

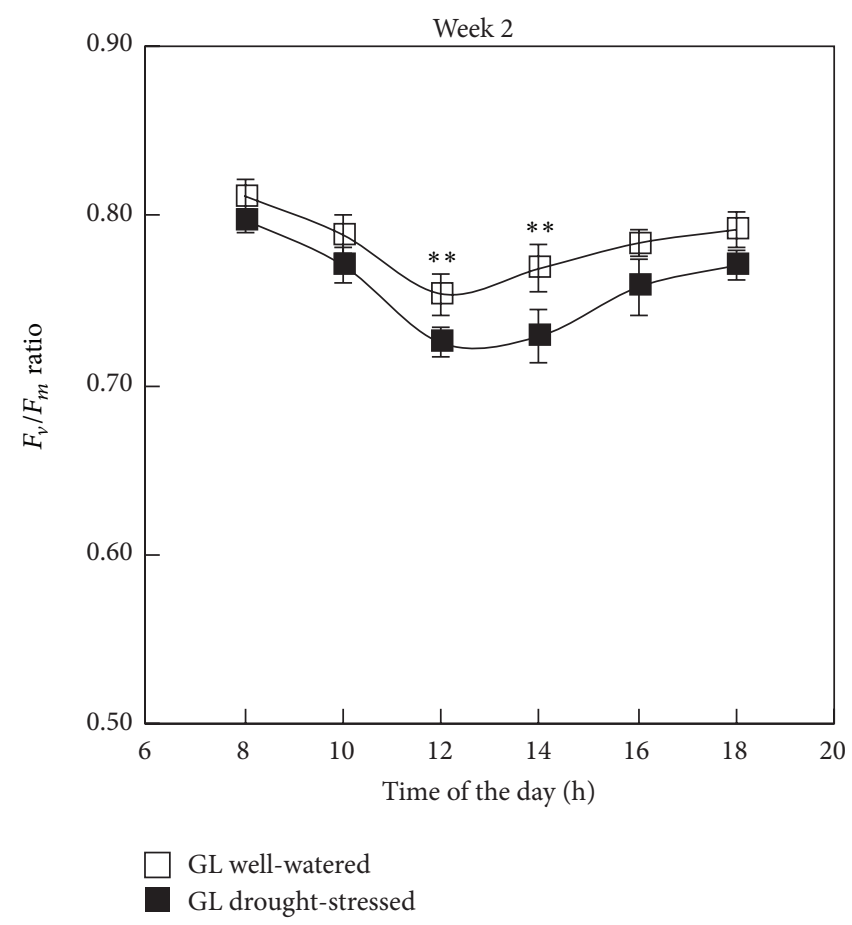

(b)

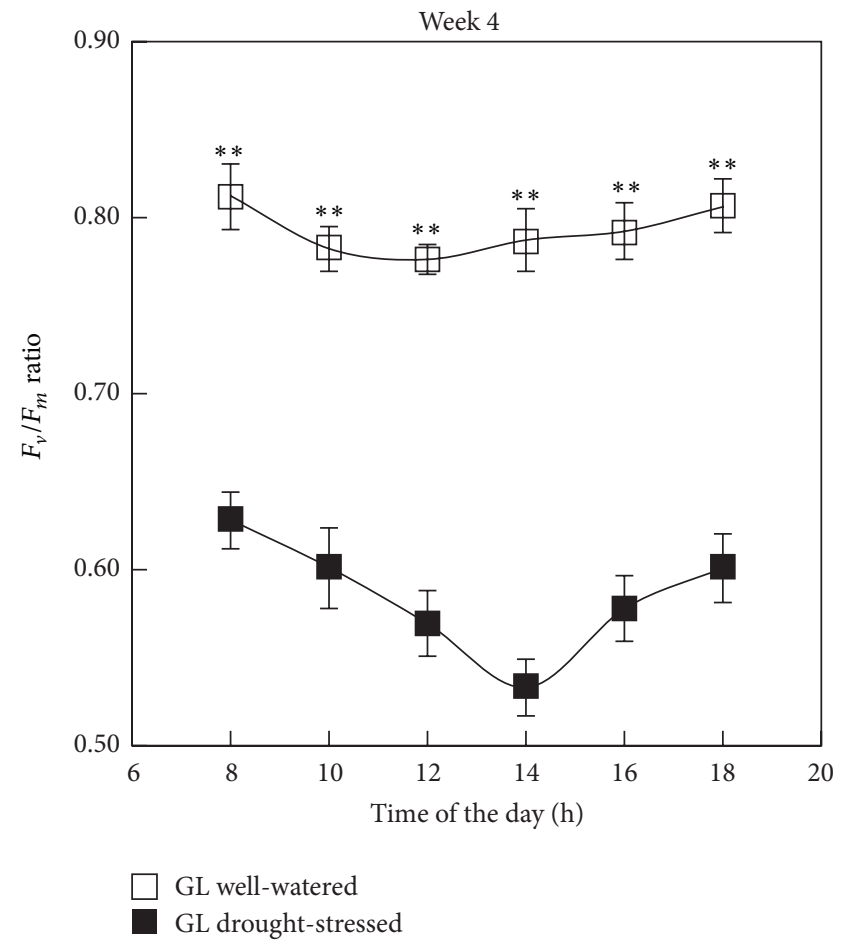

(d)

FIGURE 2: Diurnal changes of Chl fluorescence $F_{v} / F_{m}$ ratio after CAM orchid Cattleya laeliocattleya Aloha Case plants were subjected to drought stress for 1, 2, 3, and 4 weeks. Means of 8 measurements from 8 different plants. Vertical bars represent standard errors. When the standard error bars cannot be seen, they are smaller than the symbols. ${ }^{* *}$ Above the means of GL and GPSB of well watered plants are statistically different from the drought-stressed plants $(P<0.05)$. 


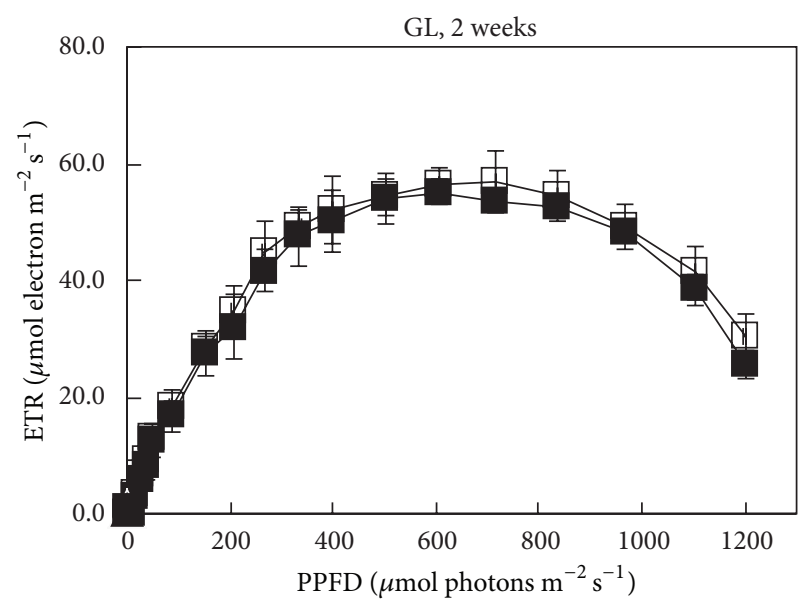

(a)

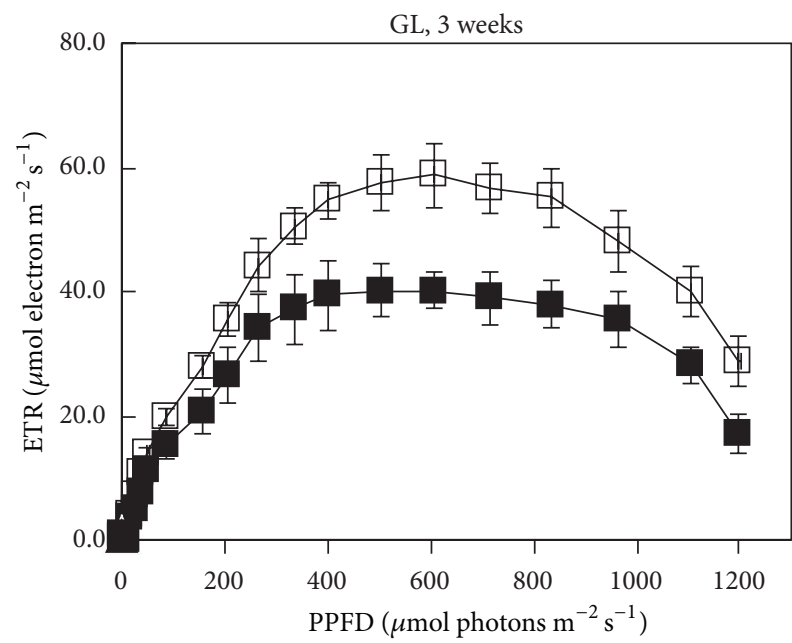

(c)

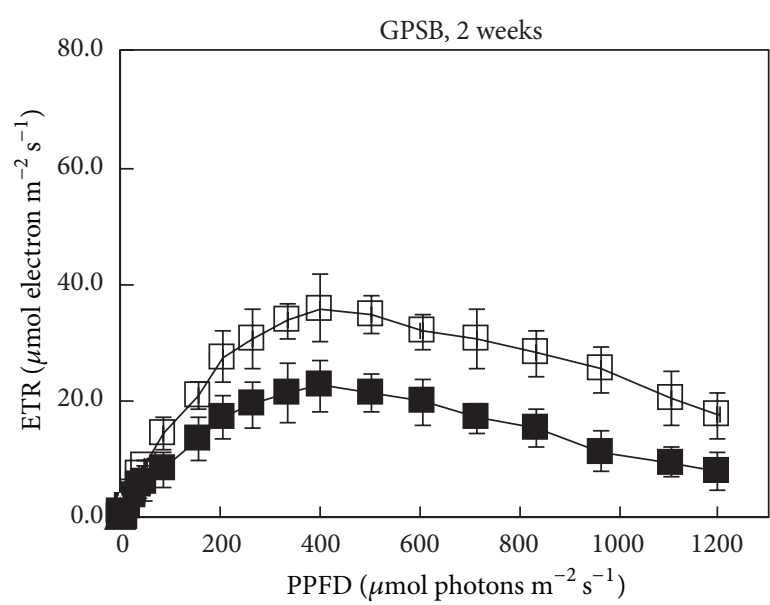

(b)

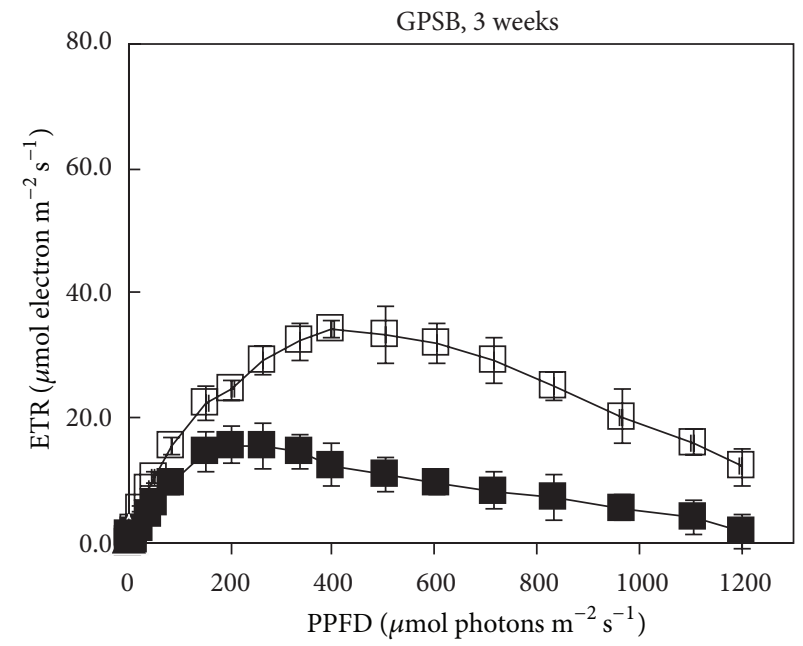

(d)

Figure 3: ETR of GL ((a), (c)) and GPSB ((b), (d)) under different PPFDs after CAM orchid Cattleya laeliocattleya Aloha Case plants were subjected to drought stress for 2 ((a), (b)) and 3 weeks ((c), (d)). Means of 5 measurements were measured from 5 different plants. Vertical bars represent standard errors. When the standard error bars cannot be seen, they are smaller than the symbols.

and the capability of using light energy was further decreased after being subjected to drought stress. For heat dissipation measured as qN, both GL and GPSB of all plants had similar treads. Values of qN increased with increasing PPFDs from 25 to $400 \mu \mathrm{mol} \mathrm{m}^{-2} \mathrm{~s}^{-1}$ (Figure 4) and after that they plateaued until the highest PPFD 6 of $1200 \mu \mathrm{mol} \mathrm{m}^{-2} \mathrm{~s}^{-1}$. However, $\mathrm{qN}$ values were lower in GL and GPSB of drought-stressed plants compared to well-watered plants after 2 and 3 weeks of treatment under PPFDs greater than $400 \mu \mathrm{mol} \mathrm{m}^{-2} \mathrm{~s}^{-1}$. The decreases were greater in drought-stressed GPSB than in drought-stressed GL, indicating that drought stress resulted in decreases of heat dissipation in both GL and GPSB with greater impact on GPSB than on GL.

\subsection{Total Chl Content and CAM Acidity after Drought Stress} Treatment. Two weeks after drought stress, there was no significant difference in total Chl content in GL between drought-stressed and well-watered plants $(P>0.05)$. However, a significant lower total Chl content was found in GL of drought-stress plants compared to well-watered plants $(P<0.05)$ after 3 weeks of treatment (Figure 5(a)). For GPSB, drought-stressed plants had a significant lower total Chl content than well-watered plants after 2 and 3 weeks of treatment with greater decrease after 3 weeks of treatment (Figure 5(b)). It was interesting to see that CAM acidity of GL significantly decreased compared to well-watered plants after 2 weeks of treatment $(P<0.05)$. This decrease was much greater after 3 weeks of drought stress (Figure 5(c)). For GPSB, significant decreases of CAM acidity in droughtstressed plants were also recorded after 2 and 3 weeks of treatment (Figure 5(d)). Decreases of CAM acidity in drought-stressed GPSB were greater than in drought-stressed GL (Figures 5(c) and 5(d)).

\section{Discussion}

The results of this study showed that there were significant decreases in WC of GL and GPSB (Figure 1(a)) and RWC 


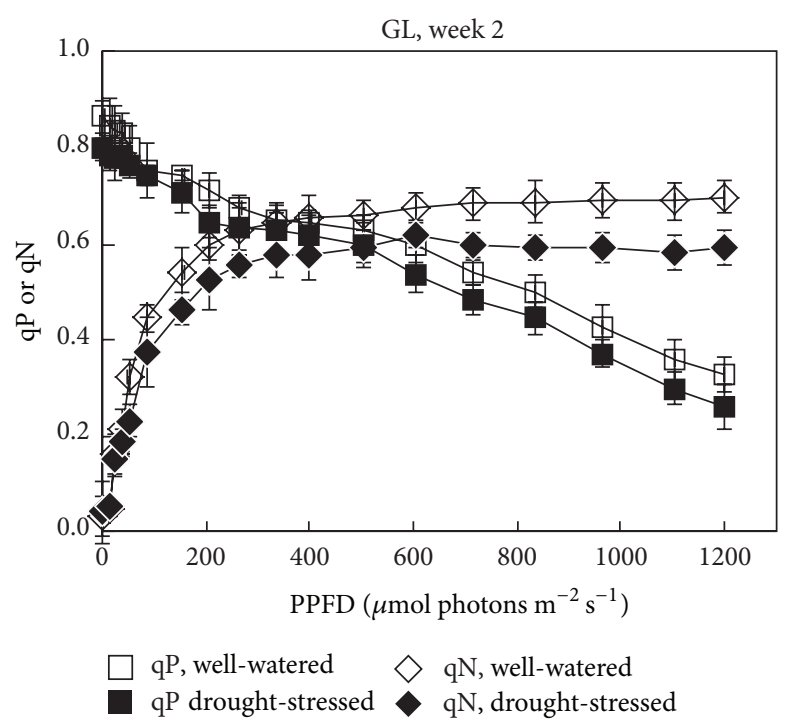

(a)

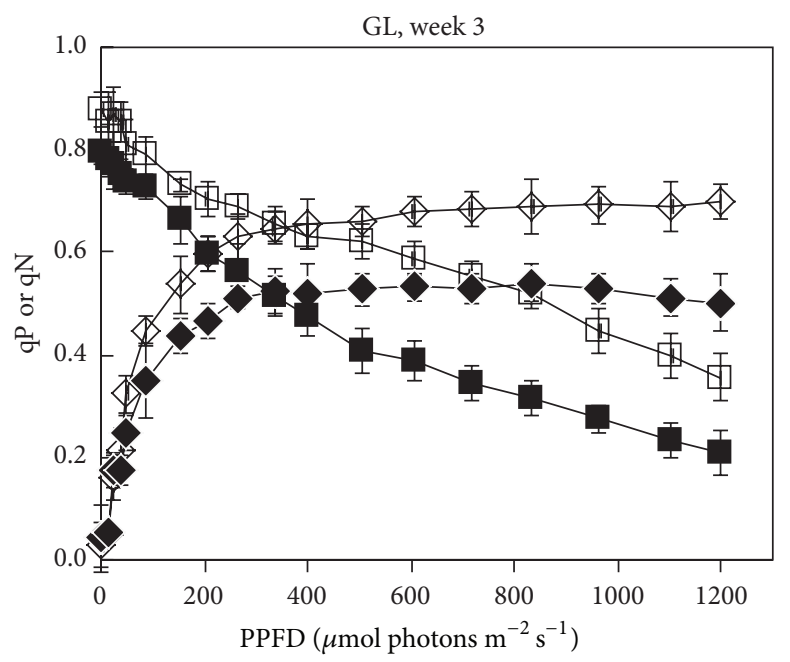

qP, well-watered $\diamond$ qN, well-watered

qP drought-stressed $\diamond$ qN, drought-stressed

(c)

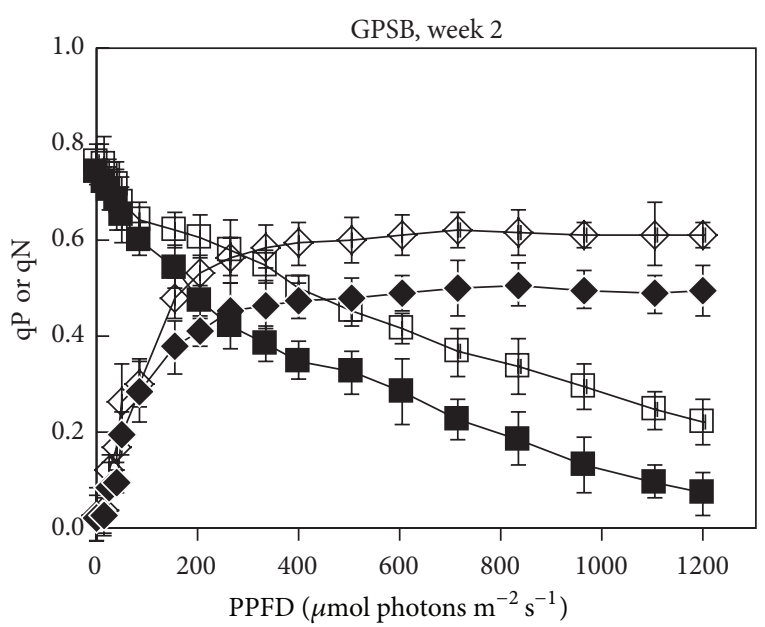

qP, well-watered $\diamond \mathrm{qN}$, well-watered

$\mathrm{qP}$ drought-stressed $\diamond \mathrm{qN}$, drought-stressed

(b)

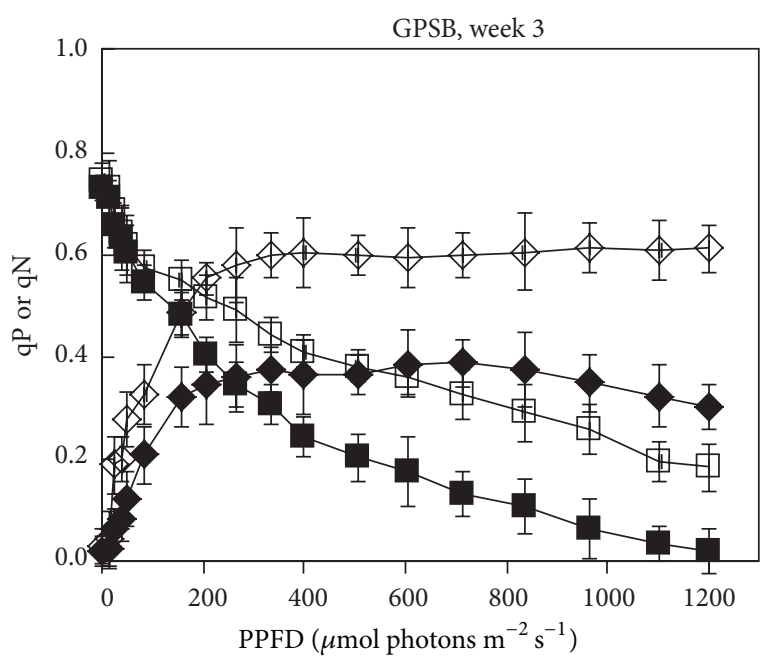

qP, well-watered $\diamond \mathrm{qN}$, well-watered

$\mathrm{qP}$ drought-stressed $\mathrm{qN}$, drought-stressed

(d)

Figure 4: qP and qN of GL ((a), (c)) and GPSB ((b), (d)) under different PPFDs after CAM orchid Cattleya laeliocattleya Aloha Case plants were subjected to drought stress for $2((\mathrm{a}),(\mathrm{b}))$ and 3 weeks $((\mathrm{c}),(\mathrm{d}))$. Means of 5 measurements were from 5 different plants. Vertical bars represent standard errors. When the standard error bars cannot be seen, they are smaller than the symbols.

of GL (Figure 1(b)) after CAM orchid Cattleya laeliocattleya Aloha Case plants were subjected to drought stress for 3 weeks. Stancato et al. [1] also observed that RWC decreased continuously in GL and GPSB of epiphytic CAM orchid (Cattleya forbesii Lindl. $\times$ Laelia tenebrosa Rolfe) after they were subjected to up 7 to 45 days of drought stress. It was also found that the decrease in WC of drought-stressed plants was greater in GPSB than in GL (Figure 1(a)). However, the decrease in WC of GPSB was one week before that of GL, indicating that GPSB facilitated a slow reduction in the leaf WC. It was further supported by the result of relative WC of GL, which was still about $80 \%$ after 2 weeks of drought stress (Figure 1(b)). In the present study, stomatal conductance was not measured in the CAM Cattleya orchid plant due to the closure of stomata even at night after being subjected to drought stress. However, the leaf RWC is a common indicator for plant water status. CAM Cattleya orchid plants under drought stress for 3 weeks were able to maintain leaf RWC above $70 \%$. This may not be possible without the presence of GPSB, which were capable of delaying excessive water loss in times of drought. As an epiphytic orchid, the GPSB are important water storage organs to provide a continual source of water in times of drought. In our previous study, we reported that the constant level of GL soluble sugar could be maintained through the mobilization of soluble and insoluble sugars of GPSB [13]. However, there were no distinct patterns in the change of sugar during drought stress treatment in the present study (data not shown). The accumulation of other 


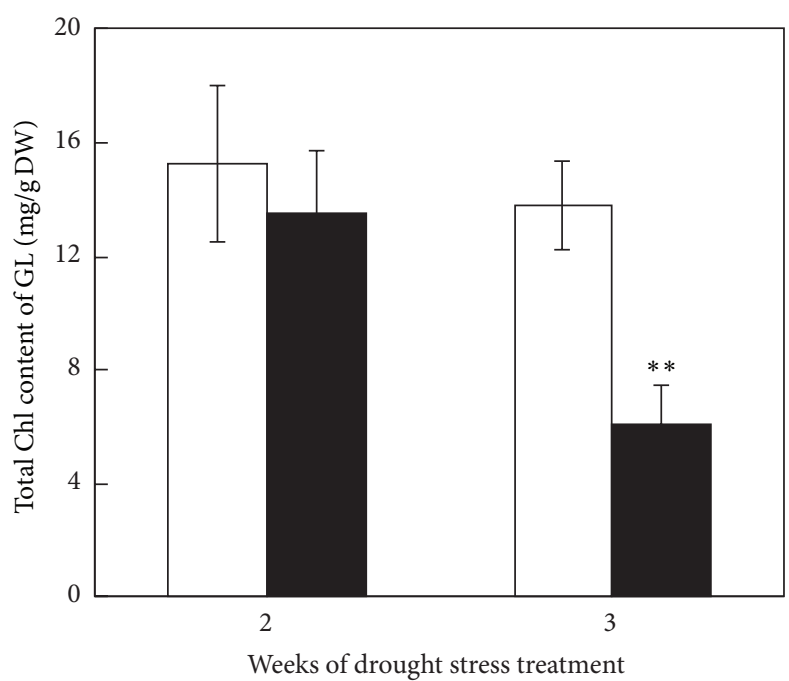

Well-watered

Drought-stressed

(a)

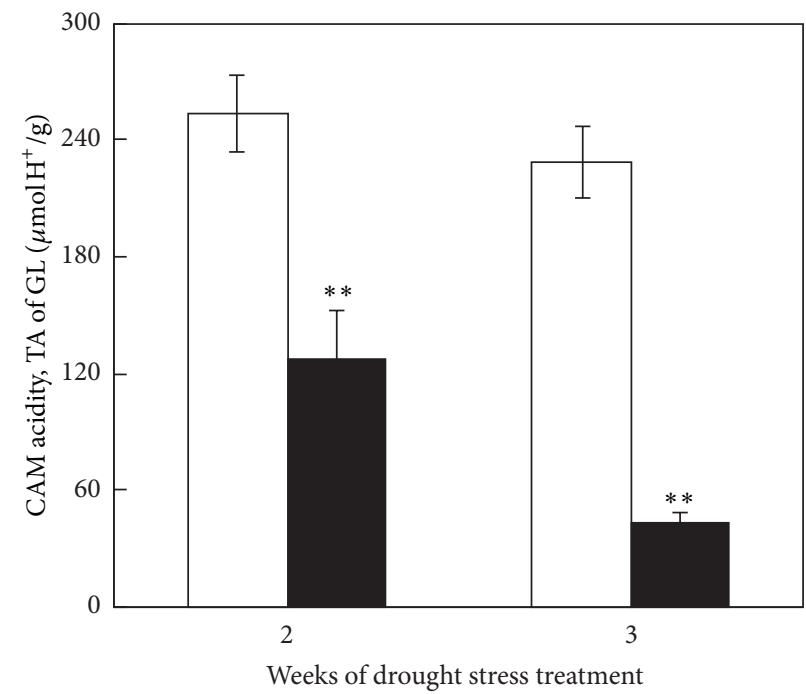

Well-watered

Drought-stressed

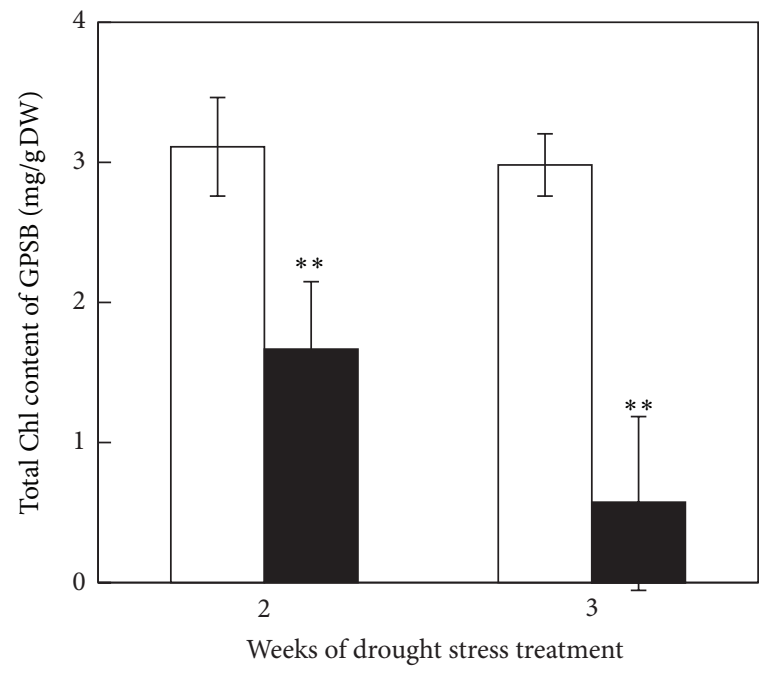

Well-watered

Drought-stressed

(b)

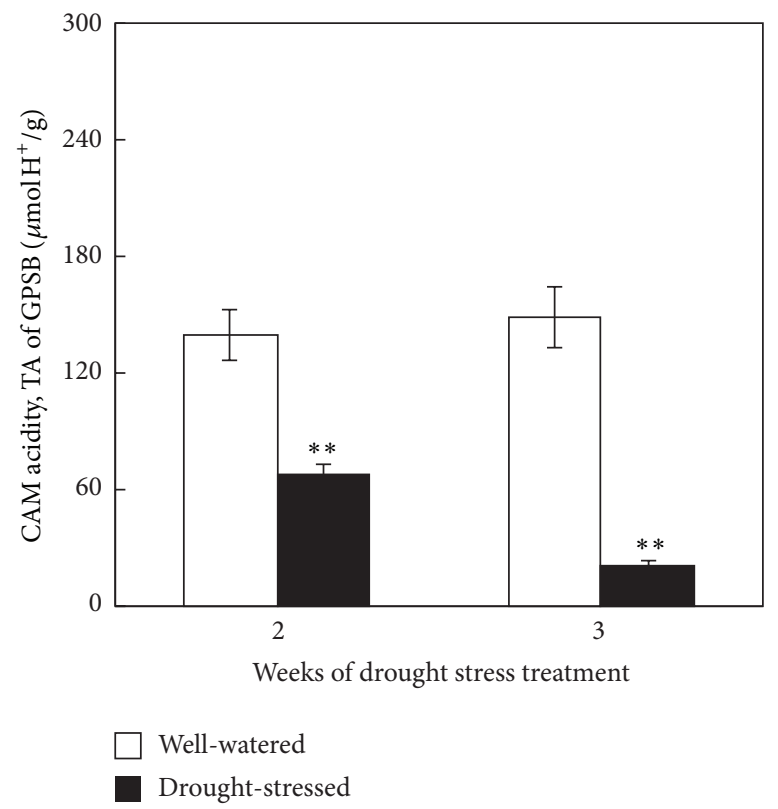

(d)

Figure 5: Total Chl content ((a), (b)) and CAM acidity ((c), (d)) and TA of GL ((a), (c)) and GPSB ((b), (d)) under different PPFDs after CAM orchid Cattleya laeliocattleya Aloha Case plants were subjected to drought stress for 2 and 3 weeks. Means of 5 measurements were measured from 5 different plants. Vertical bars represent standard errors. When the standard error bars cannot be seen, they are smaller than the symbols. ${ }^{* *}$ Above the means of GL and GPSB of drought-stressed plants are statistically different from the well-watered plants $(P<0.05)$.

osmolytes, such as proline for osmotic adjustment between GL and GPSB, merits our future studies.

Studying with epiphytic CAM orchid plants, Stancato et al. [1] found that $F_{v} / F_{m}$ ratio remained constant in well-watered plants but decreased in plants under water deficit up to 45 days. Lower $F_{v} / F_{m}$ ratio $(<0.8)$ could be an indication of photoinhibition that resulted from excessive light [17]. Photoinhibition can be dynamic or chronic. Dynamic photoinhibition is the protective downregulation of photosynthesis by diversion of electrons away from PSII by increasing nonphotochemical quenching [18]. This is common amongst sun plants and is normally a short-term reversible reduction of the photosynthetic efficiency [19]. Chronic photoinhibition, on the other hand, damages the PSII reaction centres and causes the photodestruction of the photosynthetic pigments [17]. Shade plants are especially susceptible to chronic photoinhibition following exposure to high light. It is also possible for plants growing under low light 
to suffer from chronic photoinhibition if they were subjected to drought [20]. Results of the present study showed that dynamic photoinhibition occurred in all plants. However, the effects of photoinhibition during midday in GL were more severe in drought-stressed plants than in well-watered plants (Figure 2). Chronic photoinhibition characterized by the decrease in $F_{v} / F_{m}$ ratio measured at $0800 \mathrm{~h}$ was observed in GL of drought-stressed plants after 3 and 4 weeks of treatment (Figures 2(c) and 2(d)).

With increasing drought stress, the plants suffer lower quantum yield potential of photosynthesis as a result of lesser reaction centers in PSII and result in a lower $F_{v} / F_{m}$ value throughout the day [21,22]. In addition, the reductions of ETR (Figure 3), qP, and $\mathrm{qN}$ measured under higher PPFD (Figure 4) for both GL and GPSB after drought stress suggested that GPSB were more susceptible to both drought and light stresses than GL. This is supported by the fact that the decreases in these parameters in GPSB were one week before those in GL. The greater sensitivity of GPSB to drought stress compared to GL could be due to its faster rate of water decrease after subjecting to drought stress. Studied with Triticum aestivum L plants, Hassan [23] also found that drought stress treatment, where irrigation was withheld till soil moisture of $13 \%$, reduced the levels of qP and $\mathrm{qN}$ significantly in leaves. As stated earlier, GPSB of Cattleya orchid plants also acted as a water storage source which supplied water to its GL [7]. The importance of maintaining the turgidity of GL could be due to, as shown by He et al. [13], the higher photosynthetic capability of GL as compared to other green parts. Decreases in Chl fluorescence parameters (Figures 2, 3, and 4) could be due to the changes in photosynthetic pigments under environmental stress [17, 24]. For example, Paknejad et al. [24] worked on wheat cultivars and reported that total Chl decreased with increasing drought severity of $80 \%$ soil moisture reduction. In the present study, decrease in total Chl content was much earlier, and the degree of reduced total Chl content was much greater in GL than in GPSB (Figures 5(a) and 5(b)). Decreases of total content in GL of drought-stressed plants after 3 weeks of treatment further confirmed that chronic photoinhibition (lower $F_{v} / F_{m}$ ratio at $0800 \mathrm{~h}$, Figure 2(c)) occurred in GL only after 3 weeks of drought stress treatment.

It was reported that the organic acids fixed in GL enter the GPSB at night for storage and GPSB could fix the internal respiratory $\mathrm{CO}_{2}$ into organic acid [8]. Winter et al. [14] found that under conditions of drought stress, nocturnal acidification was greatly depressed. Drought stress may cause stomata closure in GL due to water conservation. However, closure of stomata limits gaseous exchange. This reduces the amount of fixed $\mathrm{CO}_{2}$ which causes a reduction of TA content. This could explain the significantly lower dawn/dusk fluctuation of TA of GL and GPSB of drought-stressed plants as compared to well-watered plants as earlier as one week of drought stress in both GL and GPSB (Figures 5(c) and 5(d)). While CAM plants are excellent at conserving water to survive in extremely arid environments, they do not photosynthesise as efficiently and, as a result, suffer a decrease in growth [15].

\section{Conclusion}

CAM orchid Cattleya laeliocattleya Aloha Case plants were susceptible to drought stress. Drought stress had a negative impact on water content, RWC, Chl fluorescence $F_{v} / F_{m}$ ratio, ETR, qN, qP, and dawn/dusk fluctuation of TA of GL and GPSB. Compared to GL, although GPSB were more sensitive to drought stress, to a certain extent GPSB played an important role in maintaining the water level of GL. The accumulation of organic molecules such as proline for osmotic adjustment between GL and GPSB merits our future studies.

$\begin{array}{ll}\text { Abbreviations } \\ \text { Chl: } & \text { Chlorophyll } \\ \text { DW: } & \text { Dry weight } \\ \text { ETR: } & \text { Electron transport rate } \\ F_{m} \text { and } F_{v}: & \text { Maximal and variable fluorescence yields } \\ & \text { obtained from a dark-adapted sample } \\ & \text { upon application of a saturation pulse of } \\ & \text { radiation, respectively } \\ \text { FW: } & \text { Fresh weight } \\ \text { GL: } & \text { Green leaves } \\ \text { GPSB: } & \text { Green pseudobulbs } \\ \text { PPFD: } & \text { Photosynthetic photon flux density } \\ \text { PSII: } & \text { Photosystem II } \\ \text { qN: } & \text { Nonphotochemical quenching } \\ \text { qP: } & \text { Photochemical quenching } \\ \text { RWC: } & \text { Relative water content } \\ \text { SW: } & \text { Saturated weight } \\ \text { TA: } & \text { Titratable acidity } \\ \text { WC: } & \text { Water content. }\end{array}$

\section{Acknowledgments}

This project was supported by teaching materials' vote of the National Institute of Education, Nanyang Technological University, Singapore, and Academic Research Fund (RI 5/07HJ), Ministry of Education, Singapore.

\section{References}

[1] G. C. Stancato, P. Mazzafera, and M. S. Buckeridge, "Effect of a drought period on the mobilisation of non-structural carbohydrates, photosynthetic efficiency and water status in an epiphytic orchid," Plant Physiology and Biochemistry, vol. 39, no. 11, pp. 1009-1016, 2001.

[2] C. J. Goh and M. Kluge, "Gas exchange and water relations in epiphytic orchids," in VAscular Plants as Epiphytes, Evolution and Ecophysiology, U. Lüttge, Ed., pp. 139-166, Springer, Heidelberg, Germany, 1989.

[3] G. Zotz and M. T. Tyree, "Water stress in the epiphytic orchid Dimerandra emarginata (G. Meyer) hoehne," Oecologia, vol. 107, no. 2, pp. 151-159, 1996.

[4] J. B. Ertelt, "Horticultural aspects of growing and displaying a wide variety of epiphytes," Selbyana, vol. 13, pp. 95-98, 1992.

[5] X. N. Zheng, Z. Q. Wen, and C. S. Hew, "Response of Cymbidium sinense to drought stress," Journal of Hoticultural Scienc, vol. 67, pp. 295-299, 1992. 
[6] J. Arditti, "Fundamentals of orchid biology," Fundamentals of Orchid Biology, 1992.

[7] C. K. Y. Ng and C. S. Hew, "Orchid pseudobulbs "False" bulbs with a genuine importance in orchid growth and survival!", Scientia Horticulturae, vol. 83, no. 3-4, pp. 165-172, 2000.

[8] C. S. Hew and J. W. H. Yong, The Physiology of Tropical Orchids in Relation to the Industry, World Scientific Publishing, Singapore, 2nd edition, 2004.

[9] R. Sinclair, "Water relations of tropical epiphytes.I: relationships between stomatal resistance, relative water content and the components of water potential," Journal of Experimental Botany, vol. 34, no. 12, pp. 1652-1663, 1983.

[10] R. Sinclair, "Water relations of tropical epiphytes.II: performance during droughting," Journal of Experimental Botany, vol. 34, no. 12, pp. 1664-1675, 1983.

[11] S. A. Anjum, X.-Y. Xie, L.-C. Wang, M. F. Saleem, C. Man, and W. Lei, "Morphological, physiological and biochemical responses of plants to drought stress," African Journal of Agricultural Research, vol. 6, no. 9, pp. 2026-2032, 2011.

[12] S. T. Cockerham and B. Leinauer, Turfgrass Water Conservation, University of California, Agriculture and Natural Resources, Davis, Calif, USA, 2011.

[13] J. He, B. H. G. Tan, and L. Qin, "Source-to-sink relationship between green leaves and green pseudobulbs of $\mathrm{C}_{3}$ orchid in regulation of photosynthesis," Photosynthetica, vol. 49, no. 2, pp. 209-218, 2011.

[14] K. Winter, G. S. Meier, and M. M. Caldwell, "Respiratory $\mathrm{CO}_{2}$ as carbon source for nocturnal acid synthesis at high temperatures in three species exhibiting crassulacean acid metabolism," Plant Physiology, vol. 81, pp. 390-394, 1986.

[15] L. Berg, Introductory Botany: Plants, People, and the Environment, Thomson Brooks/Cole, Belmont, Calif, USA, 2nd edition, 2008.

[16] A. R. Wellburn, “The spectral determination of chlorophylls a and $b$, as well as total carotenoids, using various solvents with spectrophotometers of different resolution," Journal of Plant Physiology, vol. 144, no. 3, pp. 307-313, 1994.

[17] S. B. Powles, "Photoinhibition of photosynthesis induced by visible light," Annual Review of Plant Physiology, vol. 35, pp. 1544, 1984.

[18] F. Ghetti, G. Checcucci, and J. F. Bornman, Environmental UV Radiation: Impact on Ecosystems and Human Health and Predictive Models, Springer, Amsterdam, The Netherlands, 2001.

[19] C. B. Osmond, "What is photoinhibition? Some insights from comparisons of sun and shade plants," in Photoinhibition of Photosynthesis. From Molecular Mechanisms to the Field, N. R. Baker and J. R. Bowyer, Eds., pp. 1-24, BIOS, Oxford, UK, 1994.

[20] D. O. Hall and K. K. Rao, Photosynthesis, Cambridge University Press, UK, 6th edition, 2001.

[21] G. H. Krause and S. Somersalo, "Fluorescence as a tool in photosynthesis research: application in studies of photoinhibition, cold acclimation and freezing stress," Philosophical Transactions of the Royal Society B, vol. 323, pp. 281-293, 1989.

[22] B. Venkateswarlu, A. K. Shanker, C. Shanker, and M. Maheswari, Crop Stress and Its Management: Perspectives and Strategies, Springer, Amsterdam, The Netherlands, 2012.

[23] I. A. Hassan, "Effects of water stress and high temperature on gas exchange and chlorophyll fluorescence in Triticum aestivum L.," Photosynthetica, vol. 44, no. 2, pp. 312-315, 2006.

[24] F. Paknejad, M. Nasri, H. R. T. Moghadam, H. Zahedi, and M. J. Alahmadi, "Effects of drought stress on chlorophyll fluorescence parameters, chlorophyll content and grain yield of wheat cultivars," Journal of Biological Sciences, vol. 7, no. 6, pp. 841-847, 2007. 

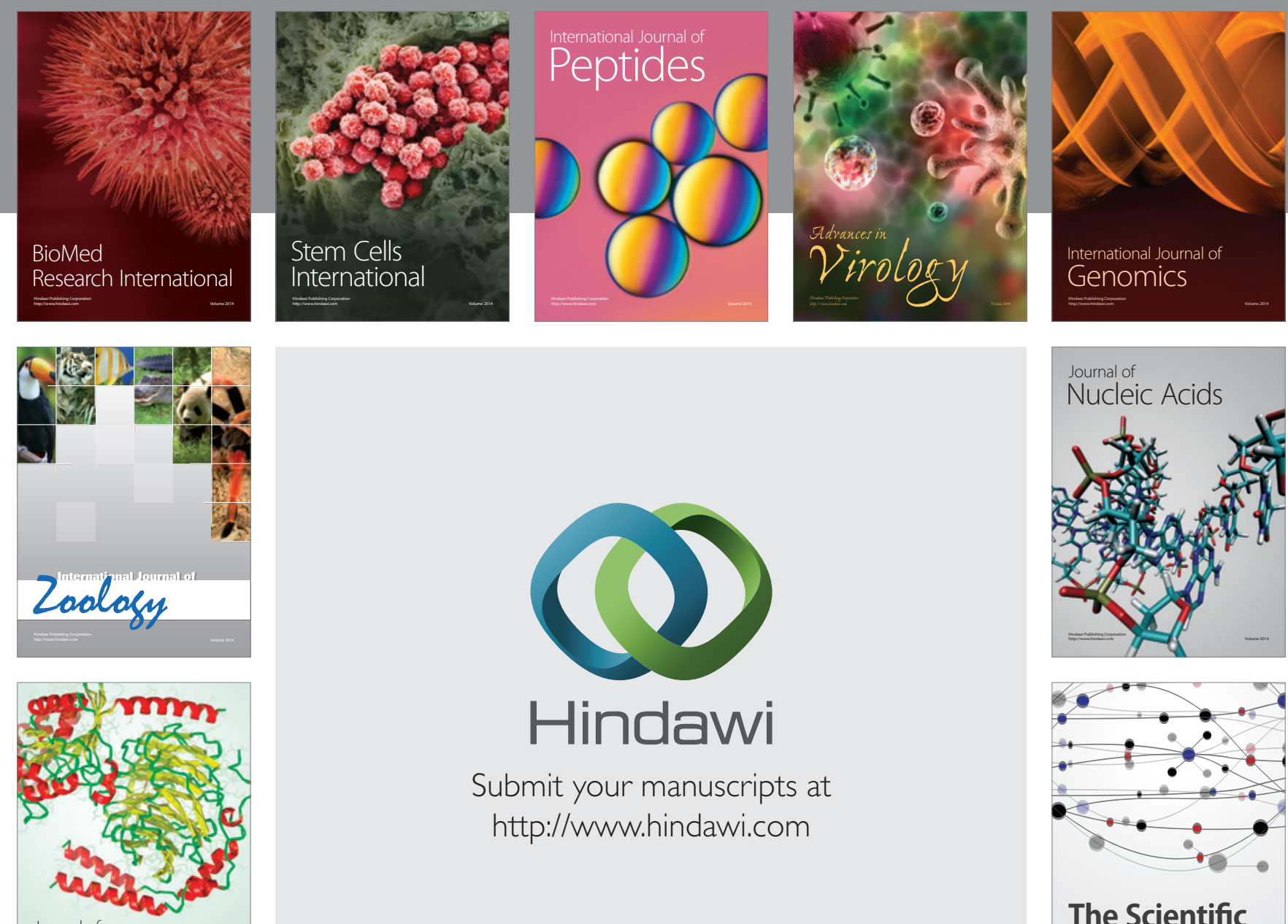

Submit your manuscripts at

http://www.hindawi.com

Journal of
Signal Transduction
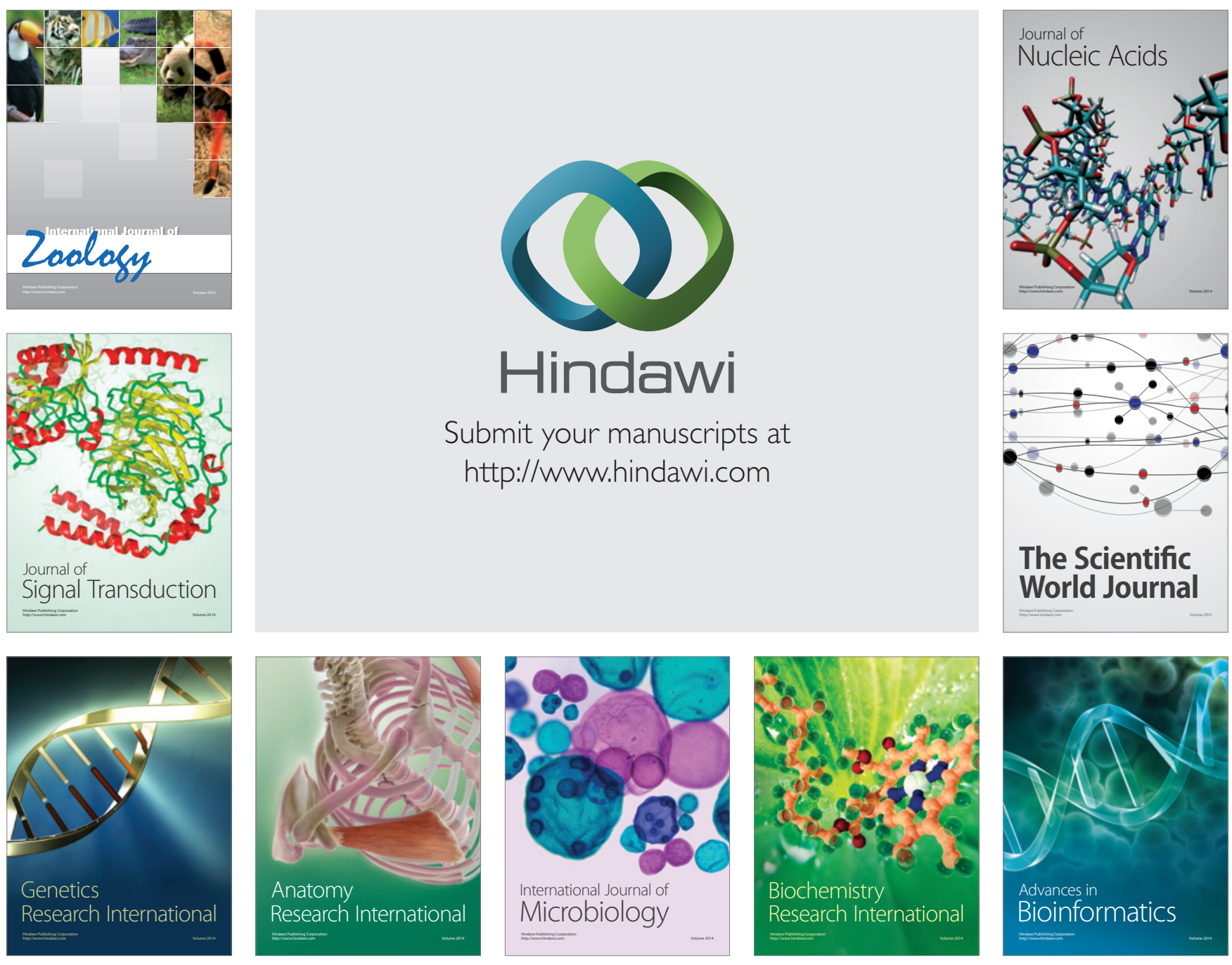

The Scientific World Journal
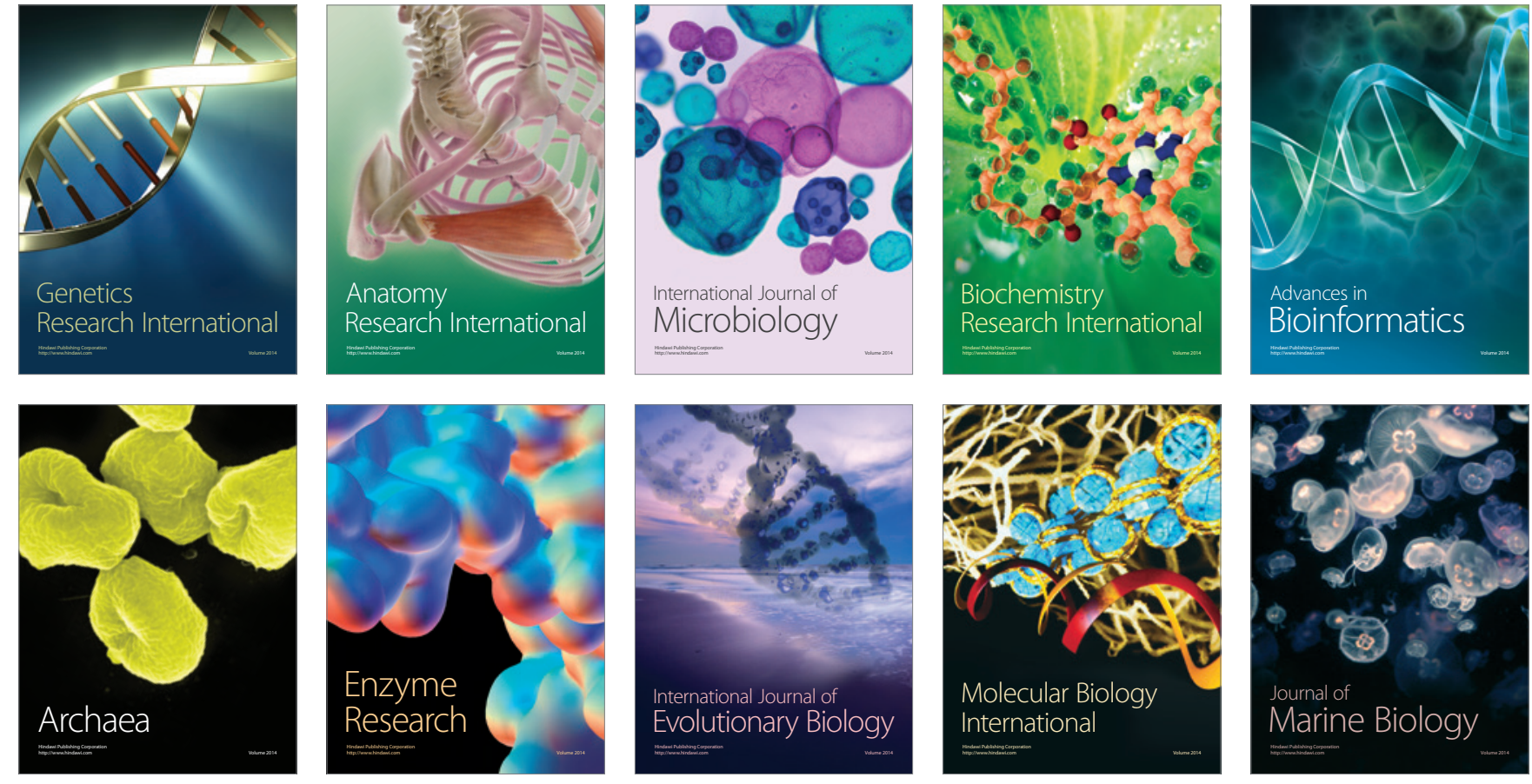